\title{
Augmented reality in healthcare education: an integrative review
}

Background. The effective development of healthcare competencies poses great educational challenges. A possible approach to provide learning opportunities is the use of augmented reality $(A R)$ where virtual learning experiences can be embedded in a real physical context. The aim of this study was to provide a comprehensive overview of the current state of the art in terms of user acceptance, the AR applications developed and the effect of AR on the development of competencies in healthcare. Methods. We conducted an integrative review. Integrative reviews are the broadest type of research review methods allowing for the inclusion of various research designs to more fully understand a phenomenon of concern. Our review included multi-disciplinary research publications in English reported until 2012. Results. 2529 research papers were found from ERIC, CINAHL, Medline, PubMed, Web of Science and Springer-link. Three qualitative, 20 quantitative and 2 mixed studies were included. Using a thematic analysis, we've described three aspects related to the research, technology and education. This study showed that AR was applied in a wide range of topics in healthcare education. Furthermore acceptance for $A R$ as a learning technology was reported among the learners and its potential for improving different types of competencies. Discussion. AR is still considered as a novelty in the literature. Most of the studies reported early prototypes. Also the designed AR applications lacked an explicit pedagogical theoretical framework. Finally the learning strategies adopted were of the traditional style 'see one, do one and teach one' and do not integrate clinical competencies to ensure patients' safety. 
1 AUGMENTED REALITY IN HEALTHCARE EDUCATION: AN INTEGRATIVE REVIEW

2 Egui Zhu ${ }^{1,2}$, Arash Hadadgar ${ }^{1}$, Italo Masiello ${ }^{1}$, Nabil Zary $^{1 *}$

$3{ }^{1}$ Department of Learning, Informatics, Management and Ethics (LIME), Karolinska Institutet, 4 Stockholm Sweden

$5 \quad{ }^{2}$ Faculty of Education, Hubei University, China

$6 *$ Corresponding author

$7 \quad$ Nabil Zary

8 Karolinska Institutet

9 Department of LIME

10 Tomtebodavägen 18A, 17177 Stockholm, Sweden

11 Tel. +46 852487129

12 Email. Nabil.Zary@ki.se

\section{Abstract}

15 Background. Developing healthcare competencies in students and professionals poses great educational challenges. A possible solution is to provide learning opportunities that utilize augmented reality (AR), where virtual learning experiences can be embedded within a real physical context. The aim of this study was to investigate the current knowledge on AR can contribute to healthcare education and the reported strengths and weaknesses of developed AR applications..

Methods. We conducted an integrative review, which is the broadest type of research review method allowing for the inclusion of various research designs. This allows us to more fully understand a phenomenon of interest. Our review included multi-disciplinary research publications in English reported until 2012.

Results. We found 2529 research papers from ERIC, CINAHL, Medline, PubMed, Web of Science and Springer-link. Three qualitative, twenty quantitative and two mixed-method studies were included. Using thematic analysis, we have described characteristics for research, technology and education. This study showed that AR was applied across a wide range of topics in healthcare education. Furthermore, acceptance for AR as a learning technology was reported among the learners, as well as its potential for improving different types of competencies. Discussion. AR is still considered a novelty in the literature, with most of the studies reporting early prototypes. Additionally, the designed AR applications lacked an explicit pedagogical theoretical framework. Instead, the learning strategies adopted were of the traditional style 'see one, do one and teach one' and do not integrate clinical competencies to ensure patients' safety. 
38

39

40

41

42

43

44

45

46

47

48

49

50

51

52

53

54

55

56
Augmented reality (AR) supplements the real world with virtual objects, such that virtual objects appear to coexist in the same space as the real world (Zhou, Duh, \& Billinghurst, 2008). It has the potential to provide powerful, contextual, and situated learning experiences, as well as to aid exploration of the complex interconnections seen in information in the real world. Students can use AR to construct new understanding based upon their interactions with virtual objects, which bring underlying data to life. AR is being applied across disciplines in higher education, including; environmental sciences, ecosystems, language, chemistry, geography and history (Johnson, Smith, Willis, Levine, \& Haywood, 2011; Klopfer \& Squire, 2007). Clinical care is also interested in AR because it provides doctors with an internal view of the patient, without the need for invasive procedures (Bajura, Fuchs, \& Ohbuchi, 1992; Chris, 2010; De Paolis, Ricciardi, Dragoni, Aloisio, \& Paolis, 2011; Lucio T. De Paolis, Pulimeno, \& Aloisio, 2008; Pandya, Siadat, $\&$ Auner, 2005). Since students and medical professionals need more situational experiences in clinical care, especially for the sake of patient safety, there is a clear need to further study the use of AR in healthcare education. The wide interest in studying AR over recent years (Rolland, 2003; Sielhorst, Obst, Burgkart, Riener, \& Navab, 2004; Thomas, John, \& Delieu, 2010) has highlighted the following beliefs:

- AR provides rich contextual learning for medical students to aid in achieving core competencies, such as decision making, effective teamwork and creative adaptation of global resources towards addressing local priorities (Frenk J, Chen L, Bhutta ZA, 2010).

- AR provides opportunities for more authentic learning and appeals to multiple learning styles, providing students a more personalized and explorative learning experience.

- The patients' safety is safeguarded if mistakes are made during skills training with AR.

While information technology has been presented as a driver for educational reforms, technology, by itself, is not a vehicle for learning (Merrill, 2002; Salomon, 2002). To prevent AR from being a gimmick with tremendous potential, it is important to understand the new capabilities that technology offers, including how those capabilities may impact learning (Garrison \& Zehra, 2009; Salinas, 2008). Therefore, a necessary first step is to analyze the current research on AR in healthcare education to determine its' strengths and weaknesses.

There are two systematic reviews about AR; one is on AR in rehabilitation to improve physical outcomes (Al-Issa, Holger, \& Hale, 12AD), and the other is focused on AR tracking techniques (Rabbi, Ullah, \& Khan, 2012). In addition to these, Lee published a literature review to describe AR applied in training and education, and discussed its potential impact on the future of education (Lee, 2012). Carmigniani and Furht developed an overview of AR technologies and their applications to different areas (Carmigniani \& Furht, 2011). Shuhaiber discussed augmented reality in the field of surgery, including its' potential in education, surgeon training and patient treatment (Shuhaiber, 2004). Thomas et al., provided a brief overview of AR for use in e-health within medicine, and specifically highlighted issues of user-centered development (Thomas et al., 2010). Ong, Shen, Zhang, and Nee presented the use of AR in assistive technology and rehabilitation engineering, focusing on the methods and application aspects (Ong, Shen, Zhang, $\&$ Nee, 2011). Of the studies include in these reviews, only two focused on medical or healthcare 
education. The first reviewed the current state of mixed reality manikins for medical education (Sherstyuk, Vincent, Berg, \& Treskunov, 2011). The second analyzed applying AR in laparoscopic surgery with a focus on training (S. M. B. I. Botden \& Jakimowicz, 2009). Both were helpful in understanding AR from different perspectives, but lacked a broader view of AR in healthcare education. Furthermore, few reviews focused on analyzing AR in relation to learning and teaching, which is important for ensuring that AR has an appropriate instructional design adapted to medical education.

The aim of this study was therefore to investigate of the current state of AR in healthcare education and its reported strengths and weaknesses of the reported AR applications for education in healthcare.

\section{Material and Methods}

We conducted an integrative review, as described by Whittemore and Knafl (2005). Integrative reviews are the broadest type of research review method and allow for the inclusion of various research designs to more fully understand a phenomenon of interest. In contrast, systematic reviews combine the evidence of primary studies, with similar research designs, to study related or identical hypotheses (Whittemore, 2005). They are more useful at providing insights about effectiveness, rather than seeking answers to more complex search questions (Grant \& Booth, 2009). Scoping reviews identify the nature and extent of research evidence to provide a preliminary assessment of the potential size and scope of available research (Grant \& Booth, 2009). However, due to lack of a process for quality assessment, the findings from scoping reviews are weak resources for recommending policy/practice. Performing an integrative review helped us to understand how AR has been applied in healthcare education, and our findings will be used to help guide better practice. Our review included multi-disciplinary research publications, reported until 2012, which were related to the construct of AR in healthcare education.

\subsection{Inclusion and exclusion criteria}

In order to present a comprehensive overview of AR relative to healthcare education, we used broad inclusion criteria. An article was included in the review if it was a research paper $(*)$, on AR (**), or on AR in healthcare education (***), and was written in English. The criteria of inclusion and exclusion were further defined as follows in table 1:

\section{Table 1 The inclusion and exclusion criteria}

[TABLE 1 HERE]

Clarification of criteria terms:

- Research paper: There is no widespread accepted set of criteria with which to assess the quality of studies. Further, research paradigm is different across the various members of the academic community, such as developer, educator and doctor. We have not restricted the methodology and the writing style of the research papers but they should contain the following core information; clear description of the context, study aims, research question, study design, sampling, data collection and analysis, and findings. Papers were excluded if they did not describe the core information mentioned above.

- AR: augmented reality, which sometimes is referred to as 'mixed reality', or 'blended reality,' is a technology that allows a live real-time direct or indirect real-world environment to be augmented/enhanced by computer-generated virtual imagery 


\subsection{Search strategy and inclusion procedure}

Agreement about the review protocol, and inclusion and exclusion criteria was reached through discussion between EZ, NZ and IM. Relevant computerized databases were searched for eligible studies, including: ERIC, CINAHL, Medline, Web of Science, PubMed and Springer -link. Separate searches were completed for each database with no date restrictions, no methodological filter, and the language limited to English. The searches were updated until November 2012. Word groups representing the key characteristics of our study were created and combined in several ways. The first group was 'augmented reality' and included terminology with similar meaning such as 'mixed reality,' or 'blended reality.' The second group was 'medical education' and included terms like 'healthcare education,' 'health science education' and so on. The two key groups of terms used the Boolean operator '(and)' to combine with the terms one another when searching for papers to include. Also, we used symbols like 'medic * education' to include more related articles with potentially different endings.

EZ independently searched for eligible studies in the six databases using the methods above and identified each article meeting the inclusion criteria. 'Medical education' and synonyms were searched in 'all areas' in the six databases throughout the search procedure. We began by searching for 'augmented reality,' or synonyms, plus 'medical education' in all areas to get the overall data. Next, 'augmented reality,' or its' synonyms, were searched within the title or abstract field, but with 'medical education' in 'all areas.' One reason for this is that we felt the focus terms should be placed in the title or abstract. Another reason is that the papers in which augmented reality was neither in the title nor abstract, were not studying augmented reality when we reviewed them. When the abstract contained insufficient information we sometimes referred to the full text to assess eligibility. This was then discussed with NZ and IM. After confirming that the paper's title and abstract discussed augmented reality on medication education, the full text was downloaded and printed to re-read and analyze, if it met the review criteria. EZ examined and marked the full texts to select the articles that met the inclusion criteria. AH checked the excluded papers by EZ to ensure we did not leave out any papers that should include. NZ checked the full text and discussed with EZ. IM was involved in the discussions and selection process when necessary. The quality of the studies was then reviewed by all the co-authors for 
final inclusion.

\subsection{Data extraction and analysis}

177 We extracted information specifically on research, technology and learning from the included 178 studies. The characteristics and the results of the included studies were recorded with a 179 standardized data-extraction form. Data were extracted independently and in tripartite for all 180 characteristics. Three main characteristics, including research, technology and learning, and 181 eleven sub-characteristics were described through qualitative content analysis for each of the 182 included studies (Appendix I). Also, we used content analysis to describe the study design for 183 each study (Appendix I). Thematic analysis was used to identify the prominent themes that 184 describe current use of AR in healthcare education. The themes are then presented in the result 185 section in terms of strength and weakness of AR.

\section{3. Results}

\subsection{Identification of relevant studies}

Figure 1. Literature search and selection flow [FIGURE 1 HERE]

We found 2529 papers on AR in medical education in the above-mentioned six databases. After screening the titles and abstracts, we found 270 citations in the titles and 179 in the abstracts that included 'augmented reality', 'mixed reality' or 'blended reality.' These terms were selected to keep focus on the key characteristics that we wanted to scrutinize and identify. After further reading of the title and abstracts, and removal of any duplicate papers, 77 full-text papers were retrieved and reviewed in more detail. Twenty-five articles met our inclusion criteria for data extraction and were analyzed. Figure 1 shows the selection process. Papers were mainly excluded if their research aim and context were not clearly described. Some articles which seemed to discuss medical education were later excluded because they only focused on medicine or treatment, and not on healthcare education (Bruellmann, Tjaden, Schwanecke, \& Barth, 2012; Loreto, Dokkum, Gouaich, \& Laffont, 2011; Pagador et al., 2011), and vice versa, one was excluded because it discussed education of another discipline that could contribute to the health of students (Hsiao, 2012).

From the included 25 research papers focusing on AR in healthcare education, 20 were based on quantitative research methods, 3 on qualitative research methods and 2 on mixed research methods. In these studies, AR was applied on 15 healthcare related subjects. Most of studies used their own AR system and 5 groups used the same system.

\subsection{Methodological quality of the identified studies}

We chose to apply a broad inclusion criteria and no restriction with regard to the papers' methodology since research on AR is still in an early innovative phase. Methodological quality was presented adapting the Medical Education Research Study Quality Instrument (MERSQI) (Reed et al., 2007). Quality (Table 2) was assessed purely for descriptive purposes, not as grounds to exclude.

\section{Table 2 Characteristics of the included studies} [TABLE 2 HERE] 


\subsection{Use of augmented reality in healthcare education}

221

222

223

224

225

226

227

228

229

230

231

232

233

234

235

236

237

238

239

240

241

242

243

244

245

246

247

248

249

250

251

252

253

254

255

256

257

258

259

260

261

262

263

264

265

The earliest study on AR in healthcare education was published in 2002 but publications in the field take off starting in 2008 (See Appendix I). Table 3was developed to map our results on AR in healthcare education, and to give us a clearer understanding of learning paradigms and the capabilities of AR offered in current research.

Across the studies we saw high variability in the research aims and also the role of AR in healthcare education (table 3). Twelve studies focused on evidence that AR can improve learning. Seven studies were aimed at developing AR systems for healthcare education. Two studies investigated the user's acceptance of AR as a learning technology. Six studies tested AR applications. The main use of AR for learning has been to provide feedback, and eight studies used AR as a means to provide feedback to students. Two studies used AR as an innovative interface and two studies used it for simulator practice. The other studies tried AR as navigation, regenerative concept, remote assessment and training, and as a meaningful information tool. One used it to reduce resources, while another group used it to offer immersion in a scenario, and one tried to give participatory reality.

The research results showed that learners can accept AR as a learning technology, and that AR can improve the learning effect by acquisition of skills and knowledge, understanding of spatial relationships and medical concepts, enhancing learning retention and performance on cognitivepsychomotor tasks, providing material in a convenient and timely manner that shortens the learning curve, giving subjective attractiveness, and simulating authentic experiences (see Appendix I and Table 3).

\section{Table 3 Characteristics of AR in medical education}

\section{[TABLE 3 HERE]}

\section{Technical Specifications}

Most of the included papers (50\%) employed mobile laptops. Four studies used smaller mobile devices such as smart phone, tablet, PDA and e-book readers. Seven papers used stationary desktop computers. Three papers did not mention which computing system they used in their studies.

Of the included papers, $68 \%$ used a camera and marker as a tracking device. Two papers used an electromagnetic tracker but different markers; one a radiographic marker and one used anatomical landmarks. Two papers used sensors. Other tracking systems, such as hybrid optical tracker and Wi-Fi signal, were found in at least one of the included papers. One paper described using a head-and-hand tracking system, but did not provide details on the technology (Yudkowsky et al., 2012). One did not use a tracking device because they projected the virtual picture on a manikin (Pretto, Manssour, Lopes, Silva, \& Pinho, 2009).

\subsubsection{Strengths of AR in healthcare education}

We identified three themes that related to the strengths of AR in healthcare education.

\section{AR implemented in several healthcare areas and aimed at all level of learners}

AR was applied in various subjects, such as: joint injection, thoracic pedicle screw placement, 
laparoscopic surgery, administering local anesthesia, endotracheal intubation, ventriculostomy, forensic medicine, inguinal canal anatomy, diathermy, tissue engineering, alimentary canal physiology and anatomy, disease outbreak, clinical breast examination, cardiologic data, and life support training, all of which are applicable to healthcare education (see Table 3). We found that $64 \%$ of the included papers were within surgery, primarily laparoscopic surgery, which represented $44 \%(11 / 25)$. Two groups provided the majority of publications of laparoscopic surgery (S. Botden, Buzink, Schijven, \& Jakimowicz, 2007, 2008; S. Botden, Hingh, \& Jakimowicz, 2009a, 2009b; LeBlanc et al., 2010; Leblanc, Delaney, Ellis, et al., 2010; Leblanc, Delaney, Neary, et al., 2010; Leblanc, Senagore, et al., 2010). Other healthcare subject areas had only one paper included in this research.

While two studies did not mention participants, the remaining 23 studies included 713 participants representing medical staff, medical students, high school students and children, (see Table 2 and Table 3). Participants used AR to learn healthcare skills and aquire knowledge. Most of the participants were, or will be, healthcare staff, however the children and high school student participants may not pursue an education or career in healthcare in their future.

\section{AR seems useful for improving healthcare education}

Ninety-six percent of the papers claimed that AR is useful for improving healthcare education. Several aspects were elicited in the different studies such as decreased amount of practice needed, reduced failure rate, improved performance accuracy, accelerated learning, shortened learning curve, easier to capture learner's attention, better understanding of spatial relationships, provided experiences with new kinds of authentic science inquiry and improved assessment of trainees.

\section{Broad focus of research - from user acceptance, system development and testing, to the study of learning effects}

Even though every paper in this study had its own research aim and focus, together they gave us a more complete perspective of how AR is being used in healthcare education (Table 3). Two papers investigated user acceptance of AR and they claimed that participants would like to use AR instructions in their future professional life, primarily due to the perceived usefulness of AR. Six papers focused on developing AR systems and two of them tested the usefulness of the systems. One of the six studies, in addition to two other studies focused on evaluating the validity of AR systems. One paper described the usefulness, reliability and applicability of the AR system, and one tested the system value. Fourteen out of the twenty-five papers presented AR for various learning aims.

\subsubsection{Weaknesses of AR in healthcare education}

We also identified three themes around the weaknesses of AR in healthcare education.

\section{Lack of learning theories to guide the design of AR}

Of the included papers, $80 \%$ did not clearly describe which kind of learning theory was used to guide design or application of AR in healthcare education. One claimed that they used activitybased learning but did not tell us how they used it; moreover, the learning strategies are not clearly described in the paper (Sakellariou, Ward, Charissis, Chanock, \& Anderson, 2009). Two groups used standard skills, such as the manual skills of fundamentals of laparoscopic surgery or expert illustration of what is done in practice, to guide design of AR systems. The participants in 
314 these groups used the standard skills identified to perform a task. One group, which used situated 315 learning, allowed the participants to explore and navigate with AR environments, but did not 316 show any learning effect (Rasimah Che, 2011). Only one group used on location learning theory 317 and the learning strategy of collaborative inquiry and role play(Rosenbaum, Klopfer, \& Perry, 318 2007). The results indicated that incorporating the affordances of AR games and the dynamic 319 models of participatory simulations make possible new kinds of authentic science inquiry 320 experiences.

\section{Discussion}

347 In this paper, we have shown an overview of the use of AR in healthcare education, additionally, we have identified the currently reported strength and weakness. The findings suggests a potential role in healthcare education even if most of the AR applications were still in a prototype stage.

Most studies said AR is useful for healthcare education, with one exception that did not mention the learning effect of AR. AR is useful because it helps the healthcare learner to understand spatial relationships and concepts, to acquire skills and knowledge, to strengthen cognitivepsychomotor abilities, and to shorten their learning curve and prolong learning retention. Further, it increases subjective attractiveness by providing students with authentic simulated experiences. Moreover, AR offers more conveniences, such as with time.

Most of the studies used AR for learning through feedback or as a navigation system. However, a 
361 Some used AR as an innovative interface or meaningful information tool. The others tried AR for

362 remote assessment and training, or simulator practice. One used it to reduce resources.

\subsection{Comparison with existing literature}

365

366

367

368

369

370

371

372

373

374

375

376

377

378

379

380

381

382

383

384

385

386

387

Two pieces of literature relevant to healthcare education, focused on introducing several examples of using AR systems. Sherstyuk, et al. introduced human manikins with augmented sensory input for medical education (Sherstyuk et al., 2011), while Botden and Jakimowicz compared three AR systems that allow the trainee to use the same instruments currently being used in the operating room for laparoscopic surgery (S. Botden \& Jakimowicz, 2009). Al-Issa, et al. used systematic review to investigate the effectiveness of physical outcomes through use of $\mathrm{AR}$ in rehabilitation. AR is not currently included in rehabilitation training and the study also showed that research on AR in rehabilitation is still in its infancy (Al-Issa et al., 12AD). Rabbi, et al. attempted a systematic review of AR tracking techniques but did not show a result (Rabbi et al., 2012). Carmigiani and Furht focused on analysis of the technical specifications of different types of AR and pointed out the advantages and disadvantages (Carmigniani \& Furht, 2011). They also discussed AR for use in medicine and education.

This review searched six different databases to determine the characteristics of AR in healthcare education, and to distinguish the strength and weakness found in current research. It particularly focused on including studies related to healthcare education. Most of the AR applications found in this review are based on mobile computing systems, especially on laptops. It is different with Carmigniani and Furht' study where the medical AR application systems are fixed in-doors. While light mobile AR has been predicted to be feasible to develop as real-time AR applications that are locally processed, our findings show that there are still very few examples of light mobile AR (Carmigniani \& Furht, 2011). In our review, we aimed to not only describe the research outcome and learning effect of included papers, but also to check which kind of learning theory was used and how they used it.

\subsection{AR and Educational Theory}

Although each study presented a clear research aim, few suggestions were given for choosing an AR model that is better for healthcare education. Moreover, there is not enough evidence to inform the design of suitable learning activities with AR system, where knowledge and skill development could be integrated into the learner's world. Thus, further research in this area should be taken to clarify the appropriate AR model, instructional designs and how to effectively use AR for healthcare education.

\subsection{Study strengths and limitations}

To our knowledge, this is the first integrative review that specifically addresses AR in healthcare relative to education. We explored how AR was applied in healthcare education encompassing a broad range of learners, learning strategy, outcomes and study designs. Content analysis and thematic analysis were useful to provide a comprehensive understanding on AR in healthcare education.

This review tries to provide a comprehensive description of AR in healthcare education with no research methodology filter. However, it is possible that some studies were missed if the key words did not appear on the tile or abstract. The studies were also limited by excluding any non- 
406

407

408

409

410

411

412

413

414

415

416

417

418

419

420

421

422

423

424

425

426

427

428

429

430

431

432

433

434

435

436

437

438

439

440

441

442

English studies. This was not only because most of papers were published in English, but also because the authors come from different countries, and English allowed them to reach a consensus on the articles to include in the analysis. It is useful to minimize bias, but we possibility excluded some important papers. Further, an interesting AR application could have been missed because they did not publish a research paper.

\section{Conclusions}

AR is in the early stages of application within healthcare education but it has enormous potential for promoting learning in healthcare based on this review of preliminary AR studies. The infancy of AR in healthcare education requires more than the testing and improvement of prototype products, but also needs to identify appropriate learning theories to better guide application of AR in healthcare education.

\section{Acknowledgements}

We wish to thank Anneliese Lilienthal for her role in reviewing this manuscript as a native English speaker, and helping to improve the quality of the language presented here.

\section{References}

Al-Issa, H., Holger, R., \& Hale, L. (12AD). Augmented reality applications in rehabilitation to improve physical outcomes.pdf. Physical Therapy Reviews, 12, 16-28. doi:10.1179/1743288X11Y.0000000051

Bajura, M., Fuchs, H., \& Ohbuchi, R. (1992). Merging Virtual Objects with the Real World : Seeing Ultrasound Imagery within the Patient. ACM SIGGRAPH Computer Graphics, 26(2), 203-210. doi:10.1145/133994.134061

Botden, S., Buzink, S., Schijven, M., \& Jakimowicz, J. (2007). Augmented versus virtual reality laparoscopic simulation: what is the difference? A comparison of the ProMIS augmented reality laparoscopic simulator versus LapSim virtual reality laparoscopic simulator. World Journal of Surgery, 31(4), 764-72. doi:10.1007/s00268-006-0724-y

Botden, S., Buzink, S., Schijven, M., \& Jakimowicz, J. (2008). ProMIS augmented reality training of laparoscopic procedures face validity. Simulation in Healthcare: Journal of the Society for Simulation in Healthcare, 3(2), 97-102. doi:10.1097/SIH.0b013e3181659e91

Botden, S., Hingh, I., \& Jakimowicz, J. (2009a). Meaningful assessment method for laparoscopic suturing training in augmented reality. Surgical Endoscopy, 23(10), 2221-8. doi:10.1007/s00464-008-0276-3

Botden, S., Hingh, I., \& Jakimowicz, J. (2009b, September). Suturing training in Augmented Reality: gaining proficiency in suturing skills faster. Surgical Endoscopy. doi:10.1007/s00464-008-0240-2

Botden, S. M. B. I., \& Jakimowicz, J. J. (2009). What is going on in augmented reality simulation in laparoscopic surgery? Surgical Endoscopy, 23(8), 1693-700. doi:10.1007/s00464-0080144-1 
443

444

445

446

447

448

449

450

451

452

453

454

455

456

457

458

459

460

461

462

463

464

465

466

467

468

469

470

471

472

473

474

475

476

477

478

479

480

Bruellmann, D. D., Tjaden, H., Schwanecke, U., \& Barth, P. (2012). An optimized video system for augmented reality in endodontics: a feasibility study. Clinical Oral Investigations. doi:10.1007/s00784-012-0718-0

Carmigniani, J., \& Furht, B. (2011). Augmented Reality: An Overview. In B. Furht (Ed.), Handbook of Augmented Reality (Vol. Springer S, pp. 3-46). Springer New York. doi:10.1145/1103900.1103926

Chris, C. (2010). How Augmented Reality Helps Doctors Save Lives - ReadWrite. Retrieved March 15, 2013, from http://readwrite.com/2010/06/02/how_augmented_reality_helps_doctors_save_lives

De Paolis, L., Ricciardi, F., Dragoni, A. F., Aloisio, G., \& Paolis, L. T. De. (2011). An Augmented Reality Application for the Radio Frequency Ablation of the Liver Tumors. In B. Murgante, O. Gervasi, A. Iglesias, D. Taniar, \& B. Apduhan (Eds.), Computational Science and Its Applications ICCSA 2011 (Vol. 6785, pp. 572-581). Springer Berlin / Heidelberg. Retrieved from http://dx.doi.org/10.1007/978-3-642-21898-9_47

Frenk J, Chen L, Bhutta ZA, et al. (2010). HEALTH PROFESSIONALS FOR A NEW : Transforming education to strengthen health systems in an interdependent world. Lancet 2010 (pp. 1-116).

Garrison, D. R., \& Zehra, A. (2009). Role of instructional technology in the transformation of higher education.pdf. Comput High Educ, 21(Springer Science+Business Media, LLC 2009), 19-30.

Grant, M. J., \& Booth, A. (2009). A typology of reviews: an analysis of 14 review types and associated methodologies. Health Information and Libraries Journal, 26(2), 91-108. doi:10.1111/j.1471-1842.2009.00848.x

Hsiao, K.-F. (2012). Using augmented reality for students health - case of combining educational learning with standard fitness. Multimedia Tools and Applications. doi:10.1007/s11042-0110985-9

Jan, U., Noll, C., \& Albrecht, U. (2012). mARble - Augmented Reality in Medical Education.pdf.

Johnson, L., Smith, R., Willis, H., Levine, A., \& Haywood, K. (2011). The 2011 Horizon Report. (New Media Consortium Educause Association, Ed.)Media (Vol. 2010, p. 36). The New Media Consortium. Retrieved from http://wp.nmc.org/horizon2011/

Karthikeyan, A., Mani, P., Balasubramaniyan, S., \& Selvam, P. (2012). Use of Augmented Reality in Serious Game for Training Medical Personnel. In N. Meghanathan, N. Chaki, \& D. Nagamalai (Eds.), Advances in Computer Science and Information Technology. Computer Science and Engineering (Vol. 85, pp. 222-230). Berlin, Heidelberg: Springer Berlin Heidelberg. doi:10.1007/978-3-642-27308-7

Klopfer, E., \& Squire, K. (2007). Environmental Detectives - the development of an augmented reality platform for environmental simulations. Educational Technology Research and 
482

483

484

485

486

487

488

489

490

491

492

493

494

495

496

497

498

499

500

501

502

503

504

505

506

507

508

509

510

511

512

513

514

515

516

517

LeBlanc, F., Champagne, B. J., Augestad, K. M., Neary, P. C., Senagore, A. J., Ellis, C. N., \& Delaney, C. P. (2010). A comparison of human cadaver and augmented reality simulator models for straight laparoscopic colorectal skills acquisition training. Journal of the American College of Surgeons, 211(2), 250-255. Retrieved from http://www.ncbi.nlm.nih.gov/pubmed/20670864

Leblanc, F., Delaney, C., Ellis, C., Neary, P., Champagne, B., \& Senagore, A. (2010). Handassisted versus straight laparoscopic sigmoid colectomy on a training simulator: what is the difference? A stepwise comparison of hand-assisted versus straight laparoscopic sigmoid colectomy performance on an augmented reality simulator. World Journal of Surgery, 34(12), 2909-14. doi:10.1007/s00268-010-0765-0

Leblanc, F., Delaney, C., Neary, P., Rose, J., Augestad, K., Senagore, A., ... Champagne, B. (2010). Assessment of comparative skills between hand-assisted and straight laparoscopic colorectal training on an augmented reality simulator. Diseases of the Colon and Rectum, 53(9), 1323-7. doi:10.1007/DCR.0b013e3181e263f1

Leblanc, F., Senagore, A., Ellis, C., Champagne, B., Augestad, K., Neary, P., \& Delaney, C. (2010). Hand-assisted laparoscopic sigmoid colectomy skills acquisition: augmented reality simulator versus human cadaver training models. Journal of Surgical Education, 67(4), 2004. doi:10.1016/j.jsurg.2010.06.004

Lee, B. K. (2012). Augmented Reality in Education and Training, (April), 13-21.

Loreto, I. Di, Dokkum, L. Van, Gouaich, A., \& Laffont, I. (2011). Mixed Reality as a Means to Strengthen Post-stroke Rehabilitation. In R. Shumaker (Ed.), Virtual and Mixed Reality, Part II (pp. 11-19). (C) Springer-Verlag Berlin Heidelberg.

Lucio T. De Paolis, Pulimeno, M., \& Aloisio, G. (2008). An Augmented Reality Application for Minimally Invasive Surgery. In 14th Nordic-Baltic Conference on Biomedical Engineering and Medical Physics IFMBE Proceedings (pp. 489-492).

Merrill, M. D. (2002). Effective Use of Instructional Technology Requires Educational Reform. Educational Technology, 42(ISSN/0013/1962), 13/16. Retrieved from http://kib.summon.serialssolutions.com/en/document/show?id=FETCHeric_primary_EJ6649361\&s.dym=false\&s.q=Author\%3A\%22Merrill\%2C+M.+David\%22

Milgram, P., \& Colquhoun, H. (1999). A Taxonomy of Real and Virtual World Display Integration. In Y. Ohta \& H. Tamura (Eds.), Environments (pp. 1-26). Springer. Retrieved from http://citeseerx.ist.psu.edu/viewdoc/summary?doi=10.1.1.32.6230

Nischelwitzer, A., Lenz, F., Searle, G., \& Holzinger, A. (2007). Some Aspects of the Development of Low-Cost Augmented Reality Learning Environments as Examples for Future Interfaces in Technology Enhanced Learning. In C. Stephanidis (Ed.), Universal Access in HCI, Part III, (pp. 728-737). Springer-Verlag Berlin Heidelberg.

518 Ong, S. K., Shen, Y., Zhang, J., \& Nee, A. Y. (2011). Augmented Reality in Assistive Technology 
Pagador, J. B., Sánchez, L. F., Sánchez, J. a, Bustos, P., Moreno, J., \& Sánchez-Margallo, F. M. (2011). Augmented reality haptic (ARH): an approach of electromagnetic tracking in minimally invasive surgery. International Journal of Computer Assisted Radiology and Surgery, 6(2), 257-63. doi:10.1007/s11548-010-0501-0

Pandya, A., Siadat, M.-R., \& Auner, G. (2005). Design, implementation and accuracy of a prototype for medical augmented reality. Computer Aided Surgery Official Journal of the International Society for Computer Aided Surgery, 10(1), 23-35. Retrieved from http://www.ncbi.nlm.nih.gov/pubmed/16199379

Pretto, F., Manssour, I. H., Lopes, M. H. I., Silva, E. R. da, \& Pinho, M. S. (2009). Augmented reality environment for life support training. In SAC'09 Proceedings of the 2009 ACM symposium on Applied Computing (pp. 836-841).

Rabbi, I., Ullah, S., \& Khan, S. U. (2012). Augmented Reality Tracking Techniques_a systematic literature.pdf. IOSR Journal of Computer Engineering (IOSRJCE), 2(2), 23-29.

Rasimah Che. (2011). Evaluation of user acceptance of mixed reality technology. Australasian Journal of Educational Technology, 27(8), 1369-1387. Retrieved from http://www.ascilite.org.au/ajet/ajet27/rasimah.html

Reed, D. A., Cook, D. A., Beckman, T. J., Levine, R. B., Kern, D. E., \& Wright, S. M. (2007). Association between funding and quality of published medical education research. JAMA : The Journal of the American Medical Association, 298(9), 1002-9. doi:10.1001/jama.298.9.1002

Rolland, J. (2003). DEVELOPMENT OF A TRAINING TOOL FOR ENDOTRACHEAL INTUBATION : In J. D. Westwood (Ed.), Medicine Meets Virtual Reality II (IOS Press., pp. 288-294).

Rosenbaum, E., Klopfer, E., \& Perry, J. (2007). On Location Learning: Authentic Applied Science with Networked Augmented Realities. Journal of Science Education and Technology, 16(1), 31-45. doi:10.1007/s10956-006-9036-0

Sakellariou, S., Ward, B. M., Charissis, V., Chanock, D., \& Anderson, P. (2009). Design and Implementation of Augmented Reality Environment for Complex Anatomy Training : Inguinal Canal Case Study, 605-614.

Salinas, M. F. (2008). From Dewey to Gates: A model to integrate psychoeducational principles in the selection and use of instructional technology. Computers \& Education, 50(3), 652660. doi:10.1016/j.compedu.2006.08.002

Salomon, G. (2002). Technology and Pedagogy: Why Don't We See the Promised Revolution? Educational Technology, 42(0013-1962), 71 - 75. Retrieved from http://kib.summon.serialssolutions.com/en/document/show?id=FETCHMERGEDeric_primary_EJ6649221\&s.q=Technology++and++pedagogy $\% 3 \mathrm{~A}+$ Why ++ don 
Sherstyuk, A., Vincent, D., Berg, B., \& Treskunov, A. (2011). Mixed reality Manikins for Medical Education. In B. Berg \& A. Treskunov (Eds.), Handbook of Augmented reality (p. 4790500). Springer Science+Business Media, LLC. Retrieved from

562 Shuhaiber, J. H. (2004). Augmented Reality in Surgery. ARCH SURG, 139, 170-174.

563

564

565

566

567

568

569

570

571

572

573

574

575

576

577

578

579

580

581

582

583

584

585

586

587

588

589

590

591

592

593

594

Sielhorst, T., Obst, T., Burgkart, R., Riener, R., \& Navab, N. (2004). An Augmented Reality Delivery Simulator for Medical Training. Nature Medicine, 7(6), 11-20. doi:10.1007/s11517-007-0231-9

Swanwick, T., \& Buckley, G. (2010). Understanding Medical Education Evidence, Theory and Practice. (T. Swanwick, Ed.) (pp. xv-xvii). London: WILEY-BLACKWELL. Retrieved from http://www.google.se/books? $\mathrm{id}=3 \mathrm{QvtYis} 7 \mathrm{nIMC} \&$ printsec $=$ frontcover $\# \mathrm{v}=$ onepage $\& \mathrm{q} \& \mathrm{f}=$ false

Thomas, R. G., John, N. W., \& Delieu, J. M. (2010). Augmented reality for anatomical education. Journal of Visual Communication in Medicine, 33(1), 6-15. Retrieved from http://www.ncbi.nlm.nih.gov/pubmed/20297908

Whittemore, R. (2005). Combining evidence in nursing research: methods and implications. Nursing Research, 54(1), 56-62. Retrieved from http://ovidsp.tx.ovid.com/sp3.12.0b/ovidweb.cgi?

WebLinkFrameset $=1 \& S=$ IMDGFPJOECDDGKFGNCMKIGJCBGPDAA00\&returnUrl=ov idweb.cgi?\&Full+Text=L\%7cS.sh.22.23\%7c0\%7c00006199-20050100000008\&S=IMDGFPJOECDDGKFGNCMKIGJCBGPDAA00\&directlink=http://graphics.tx. ovid.com/ovftpdfs/FPDDNCJCIGFGEC00/fs047/ovft/live/gv031/00006199/00006199200501000-00008.pdf\&filename $=$ Combining + Evidence + in + Nursing + Research: +Methods+and+Implications.\&pdf_key=FPDDNCJCIGFGEC00\&pdf_index=/fs047/

Wojtczak, A. (2002). Glossary of medical education terms: part 4. Medical Teacher, 24(5), 5678. doi:10.1080/0142159021000012667

Yudkowsky, R., Luciano, C., Banerjee, P., Schwartz, A., Alaraj, A., Lemole, G. M., ... Frim, D. (2012). Practice on an Augmented Reality/Haptic Simulator and Library of Virtual Brains Improves Residents' Ability to Perform a Ventriculostomy. Simulation in Healthcare : Journal of the Society for Simulation in Healthcare, 8(1), 25-31. doi:10.1097/SIH.0b013e3182662c69

Zhou, F., Duh, H. B., \& Billinghurst, M. (2008). Trends in augmented reality tracking, interaction and display: A review of ten years of ISMAR. 2008 7th IEEEACM International Symposium on Mixed and Augmented Reality, 2(4), 193-202. doi:10.1109/ISMAR.2008.4637362

\section{Appendix}

Appendix I: Description of 25 comparative studies included in the integrative review of AR in medical education 
595

596 [Appendix I here]

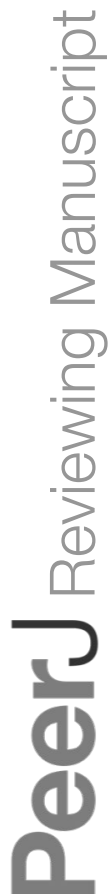

PeerJ reviewing PDF | (v2014:03:1900:2:0:NEW 14 Jun 2014) 


\section{Table 1 (on next page)}

Table 2 Characteristics of the included studies 
Table 2 Characteristics of the included studies

\begin{tabular}{|c|c|c|c|}
\hline CHARACTERISTICS & TYPES & \multicolumn{2}{|l|}{ NO OF STUDIES } \\
\hline \multirow[t]{8}{*}{ Study design } & \multirow[t]{5}{*}{ Experiment } & $\begin{array}{l}1 \text { group post-test } \\
\text { only }\end{array}$ & 2 \\
\hline & & $\begin{array}{l}1 \text { group pre-test and } \\
\text { post-test }\end{array}$ & 1 \\
\hline & & $\begin{array}{l}2 \text { groups } \\
\text { randomized }\end{array}$ & 6 \\
\hline & & $\begin{array}{l}2 \text { groups non- } \\
\text { random }\end{array}$ & 5 \\
\hline & & $\begin{array}{l}3 \text { groups non- } \\
\text { random }\end{array}$ & 4 \\
\hline & Descriptive & Interviews & 3 \\
\hline & & Questionnaire & 10 \\
\hline & & Case & 2 \\
\hline \multirow[t]{2}{*}{ Type of data } & $\begin{array}{l}\text { Self-reported } \\
\text { (participants) }\end{array}$ & \multicolumn{2}{|l|}{10} \\
\hline & Measured & \multicolumn{2}{|c|}{18} \\
\hline \multirow[t]{2}{*}{ Data analysis } & Descriptive analysis & \multicolumn{2}{|l|}{19} \\
\hline & $\begin{array}{l}\text { Other types of } \\
\text { analysis }\end{array}$ & \multicolumn{2}{|l|}{3} \\
\hline \multirow[t]{5}{*}{ Outcomes } & $\begin{array}{l}\text { Satisfaction, } \\
\text { attitudes, } \\
\text { perceptions, } \\
\text { opinions }\end{array}$ & \multicolumn{2}{|l|}{10} \\
\hline & Knowledge, skills & \multicolumn{2}{|l|}{16} \\
\hline & Experiences & \multicolumn{2}{|l|}{2} \\
\hline & Healthcare outcome & \multicolumn{2}{|l|}{0} \\
\hline & Not reported & \multicolumn{2}{|l|}{3} \\
\hline
\end{tabular}




\section{Table 2 (on next page)}

Table 1

Table 1 The inclusion and exclusion criteria 
Table 1 The inclusion and exclusion criteria

\begin{tabular}{lll}
\hline Criterion & \multicolumn{1}{c}{ Inclusion criteria } & \multicolumn{1}{c}{ Exclusion criteria } \\
\hline Research & - Clearly described the goal or & - Neither goal nor research question \\
& research question & described \\
& - A scientific study design & - Review papers were put in \\
& - The data collection and analysis & introduction \\
& methods were clearly described & \\
& - The results were clearly described & \\
\hline Focus of the & - Combination of real and virtual & - Used mixed reality in name, \\
Technology & environments & but was only virtual reality. \\
& - Interactive in real-time & \\
& - Real or perceived registration in & \\
& 3D & \\
\hline Content & - Healthcare education & - Education without medicine \\
& - Health science education & - Medicine without education \\
& - Medical education & - Veterinary medicine education \\
\hline
\end{tabular}




\section{Table 3 (on next page)}

Table 3 Characteristics of AR in medical education 


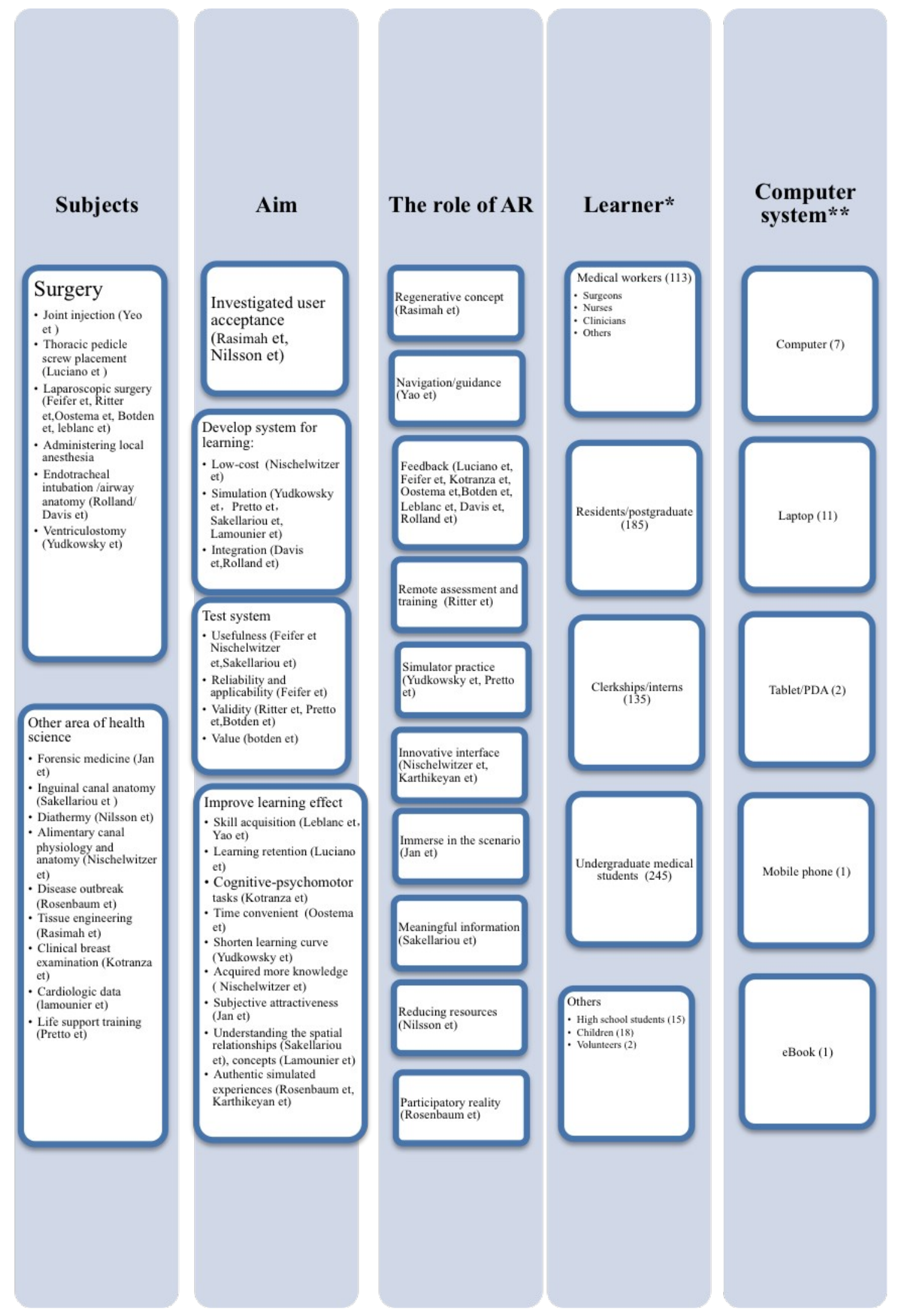

*This number is the total of unique participants for all the included papers. We used the largest 
number given for two groups (S.Botden et al \& Leblanc et al), who published 4 papers.

**This number shows the type of computer system that was used in the included papers.

Three papers did not describe a computer system (Karthikeyan, Mani, Balasubramaniyan, \& Selvam, 2012b; Sakellariou et al., 2009; Yudkowsky et al., 2012a). 


\section{Figure 1}

Figure 1

Figure 1. Literature search and selection flow 
Computerized article search $(n=2529)$ :

ERIC: 14

CINAHL: 11

Medline: 100

Web of Science: 100

PubMed: 156

Springer- link: 2158

Excluded $(n=2090)$

- Not meeting inclusion criteria

(titles and abstracts)

Full-text articles screened for AR $(n=439)$

- AR in title $(n=270)$

- $A R$ in abstract $(n=169)$

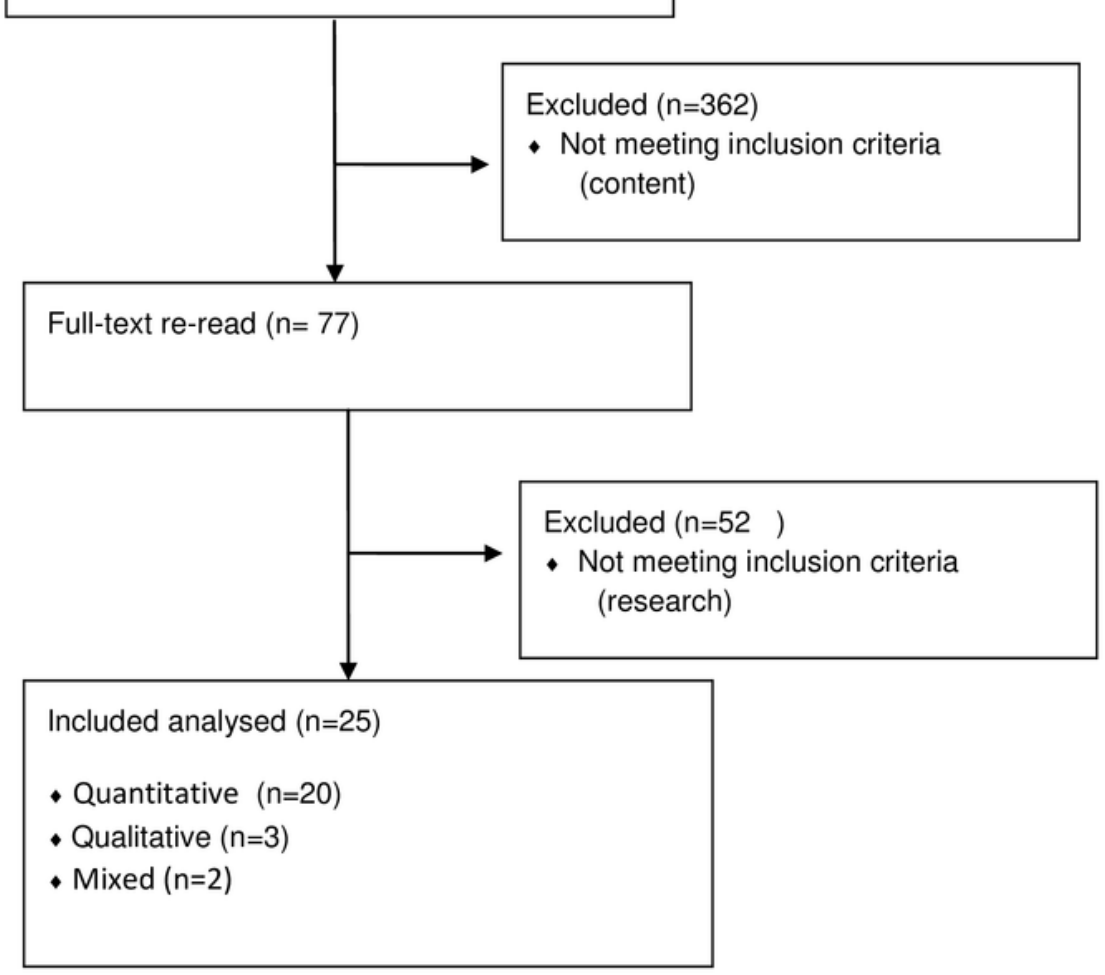

